\section{Case Reports in Dermatology}

\title{
Multiple Keratoacanthomas after a Recent Tattoo: A Case Report
}

\author{
Fouad Mitri Wolfgang Hartschuh Ferdinand Toberer \\ Department of Dermatology, University Hospital Heidelberg, Heidelberg, Germany
}

\section{Keywords}

Keratoacanthoma $\cdot$ Tattoo $\cdot$ Red dye $\cdot$ Human papillomavirus 6

\begin{abstract}
We report on a 39-year-old man who presented with seven skin lesions on the right thigh 3 weeks after receiving a large tattoo which included red and black pigments. Initially, the lesions grew fast, later their growth stabilized. Histopathology showed well-circumscribed symmetric tumors with a central keratin-filled crater along with further trademarks of a keratoacanthoma. The patient had previously had multiple tattoos with no history of similar lesions. PCR analysis of one of the lesions revealed the presence of human papillomavirus 6 . All lesions were excised with a safety margin. A 3-month follow-up revealed no further lesions.
\end{abstract}

(C) 2021 The Author(s)

Published by S. Karger AG, Basel

\section{Case Report}

A 39-year-old Caucasian man presented to our outpatient department with seven painless, non-itchy papules within a recent tattoo (Fig. 1). They appeared around 3 weeks after the patient had received a large tattoo covering the ventral aspect of the right thigh. Initially, the lesions grew rapidly, then their growth later stagnated. Physical examination revealed unilateral erythematous dome-shaped papules ranging from $4 \mathrm{~mm}$ to $1 \mathrm{~cm}$ in diameter. Five out of the seven lesions arose within the red-inked area and two within the black/gray-inked area.

\begin{tabular}{ll}
\hline & Fouad Mitri \\
& Department of Dermatology, University Hospital Heidelberg \\
Im Neuenheimer Feld 440 \\
DE-69120 Heidelberg (Germany) \\
fouad.mitri@med.uni-heidelberg.de
\end{tabular}




\section{Case Reports in Dermatology}

Case Rep Dermatol 2021;13:23-27

DOI: $10.1159 / 000510707$

Mitri et al.: Tattoo-Associated Multiple Keratoacanthomas

The papules were mostly capped with a thin crust. The patient has no past medical history and no further symptoms. He had had multiple tattoos in the past without complications. Recent sun exposure was denied.

An excisional biopsy revealed well-circumscribed symmetric tumors with a central keratin-filled crater. The cytologic atypia was mild and the tumors were accompanied by neutrophilic microabscesses and a mixed cell infiltrate (Fig. 2). Therefore, the clinical and histopathological findings were consistent with multiple keratoacanthomas (KAs).

After DNA hybridization and PCR amplification using the VisionArray ${ }^{\circledR}$ primer, human papillomavirus 6 (HPV6) (low-risk) was detected. The test was not reproducible in two further biopsies. All seven lesions were later excised with a minimal safety margin of $2 \mathrm{~mm}$. A 3-month follow-up showed no further lesions.

\section{Discussion}

KA is a common keratinizing neoplasm characterized by the proliferation of highly differentiated squamous epithelia, acute onset, rapid growth, and often spontaneous regression. Many etiologies have been suggested, including immunosuppression, trauma, ultraviolet radiation, exposure to chemical carcinogens or viruses such as HPV, use of BRAF inhibitors, as well as genetic predisposition such as mutations of $p 53$ or $H$-ras [1].

Tattooing is a common practice of intradermal pigment application with increased prevalence. Some dyes are potentially carcinogenic, such as primary aromatic amines and cleavage products of organic azo colorants [2]. 2-anisidin in red dyes acts as a co-carcinogen especially in combination with sunlight [3]. Nonmelanoma skin cancers, mainly squamous cell carcinoma (SCC) and KA, have been described in association with tattoos, with KA being the most common tattoo-associated neoplasia. In contrast, basal cell carcinomas arising within a tattoo are less frequent and probably coincidental, with only 13 reported cases [4].

The first case of multiple KAs arising in a multicolored tattoo was described in 2008 by Goldenberg et al. [5]. The differential diagnosis of KA includes pseudoepitheliomatous hyperplasia as well as SCC. Clinically, SCC usually develops years after tattooing, whereas KA develops rather rapidly [6]. Both tattoo-related KA and SCC typically present as solitary lesions. Histologically, KA has less atypia than SCC and reveals a symmetrical silhouette with a surrounding epithelium over the edges of a keratin-filled crater. Pseudoepitheliomatous hyperplasia is a benign proliferative cutaneous disorder regarded as a reactive histopathological pattern rather than a distinct entity [7].

According to Kluger et al. [8], the etiology of tattoo-related KA is multifactorial. Trauma, inflammation, and environmental factors such as exposition to ultraviolet radiation could be implicated. The role of coincidence has also been hypothesized, especially when considering the rarity of the entity relative to the tattooed population. In our case, trauma is more plausible. Localized immunosuppression, likely trauma-related, could also contribute to neoplasms [9] and increase the likelihood of an HPV infection. Interestingly, HPV DNA has been detected in 33\% of KAs [10]. Moreover, HPV6 has been reported in giant as well as subungual KA [11]. The fact that only one out of three tested lesions showed HPV DNA in the present case allows the assumption of a coincidental finding. Apart from Grzybowski syndrome and FergusonSmith disease, the etiology of multiple tattoo-related KAs is even less understood.

Most of the reported cases of tattoo-associated melanoma and basal cell carcinoma occurred on dark-colored tattoos, while SCC and KA arose primarily within the red pigment [12].

\section{Karger'=}




\section{Case Reports in Dermatology}

Mitri et al.: Tattoo-Associated Multiple Keratoacanthomas

Spectrometry demonstrated the presence of a red azo pigment in 3 patients with KAs arising from red ink [13]. Interestingly, our patient's KAs arose on both pigments. The concerned tattoo artist was unable to identify the exact pigments.

Fortunately, KA exhibits a benign natural course with no reliable reports of deaths or metastasis. Therapy options include excision or nonoperative approaches. Large KAs could be treated with intralesional methotrexate, 5-FU, or corticosteroid whereas small lesions could benefit from local imiquimod or 5-FU [14]. Furthermore, multiple lesions have been successfully treated systemically with oral acitretin as well as photodynamic therapy. Our patient's lesions were excised with clear margins upon his request.

\section{Conclusion}

Several dermatological complications have been reported as a result of tattooing. The incidence of tattoo-related skin neoplasms is rising. Here, we reported a case of multiple KAs arising from both black/gray and red ink. Many etiologies for the formation of skin tumors in tattoos have been proposed, but it is difficult to prove a direct causality. Pigment toxicology to better understand tattoo safety should be researched more. Lastly, it is important to implement standardized regulations regarding the use of pigments in tattooing.

\section{Statement of Ethics}

Formal institutional board approval was not needed. The principles outlined in the Declaration of Helsinki were followed. The patient gave his written informed consent for his images and clinical information to be reported in this medical publication.

\section{Conflict of Interest Statement}

The authors have no conflicts of interest to declare.

\section{Funding Sources}

The authors received no financial support for the research, authorship, and/or publication of this article.

\section{Author Contributions}

All authors had full access to the data and take responsibility for the integrity of the data and the accuracy of the analysis. All authors contributed to the preparation of the manuscript. Particularly, Prof. Hartschuh conducted the histology along with Dr. Toberer. Writing and editing were performed by Dr. Mitri and Dr. Toberer.

\section{Karger'=}




\section{Case Reports in Dermatology}

\section{References}

1 Zito PM, Scharf R. Keratoacanthoma. Treasure Island, FL: StatPearls Publishing; 2020. www.ncbi.nlm.nih.gov/books/NBK499931/.

2 Laux P, Tralau T, Tentschert J, Blume A, Dahouk SA, Bäumler W, et al. A medical-toxicological view of tattooing. Lancet. 2016 Jan;387(10016):395-402.

3 Lerche CM, Heerfordt IM, Serup J, Poulsen T, Wulf HC. Red tattoos, ultraviolet radiation and skin cancer in mice. Exp Dermatol. 2017 Nov;26(11):1091-6.

4 Kluger N, Koljonen V. Tattoos, inks, and cancer. Lancet Oncol. 2012 Apr;13(4):e161-8.

5 Goldenberg G, Patel S, Patel MJ, Williford P, Sangueza O. Eruptive squamous cell carcinomas, keratoacanthoma type, arising in a multicolor tattoo. J Cutan Pathol. 2008 Jan;35(1):62-4.

6 Junqueira AL, Wanat KA, Farah RS. Squamous neoplasms arising within tattoos: clinical presentation, histopathology and management. Clin Exp Dermatol. 2017 Aug;42(6):601-6.

7 Weedon D. Tumor of the epidermis. In: Weedon D, Strutton G, editors. Skin Pathology. New York: Churchill Livingstone; 2002. p. 753-802.

8 Kluger N, Douvin D, Dupuis-Fourdan F, Doumecq-Lacoste JM, Descamps V. Keratoacanthomas on recent tattoos: two cases. Ann Dermatol Venereol. 2017 Dec;144(12):776-83. French.

9 Ruocco V, Brunetti G, Puca RV, Ruocco E. The immunocompromised district: a unifying concept for lymphoedematous, herpes-infected and otherwise damaged sites. J Eur Acad Dermatol Venereol. 2009 Dec;23(12):1364-73.

10 Saftic M, Batinac T, Zamolo G, Coklo M, Simat M, Mustac E, et al. HPV 6-positive giant keratoacanthoma in an immunocompetent patient. Tumori. 2006 Jan-Feb;92(1):79-82.

11 Göktay F, Kaynak E, Güneș P, Yașar Ș, Küçükodacı Z, Aytekin S. Relationship between Human Papilloma Virus and Subungual Keratoacanthoma: Two Case Reports and the Outcomes of Surgical Treatment. Skin Appendage Disord. 2017 Jan;2(3-4):92-6.

12 Maxim E, Higgins H, D'Souza L. A case of multiple squamous cell carcinomas arising from red tattoo pigment. Int J Womens Dermatol. 2017 Aug;3(4):228-30.

13 Colboc H, Bazin D, Moguelet P, Reguer S, Amode R, Jouanneau C, et al. Chemical composition and distribution of tattoo inks within tattoo-associated keratoacanthoma. J Eur Acad Dermatol Venereol. 2020 Jul;34(7): e313-5.

14 Seger EW, Tarantino IS, Neill BC, Wang T. Relative Efficacy of Nonoperative Treatment of Keratoacanthomas. J Cutan Med Surg. 2020 Jan/Feb;24(1):41-6. 


\section{Case Reports in Dermatology}

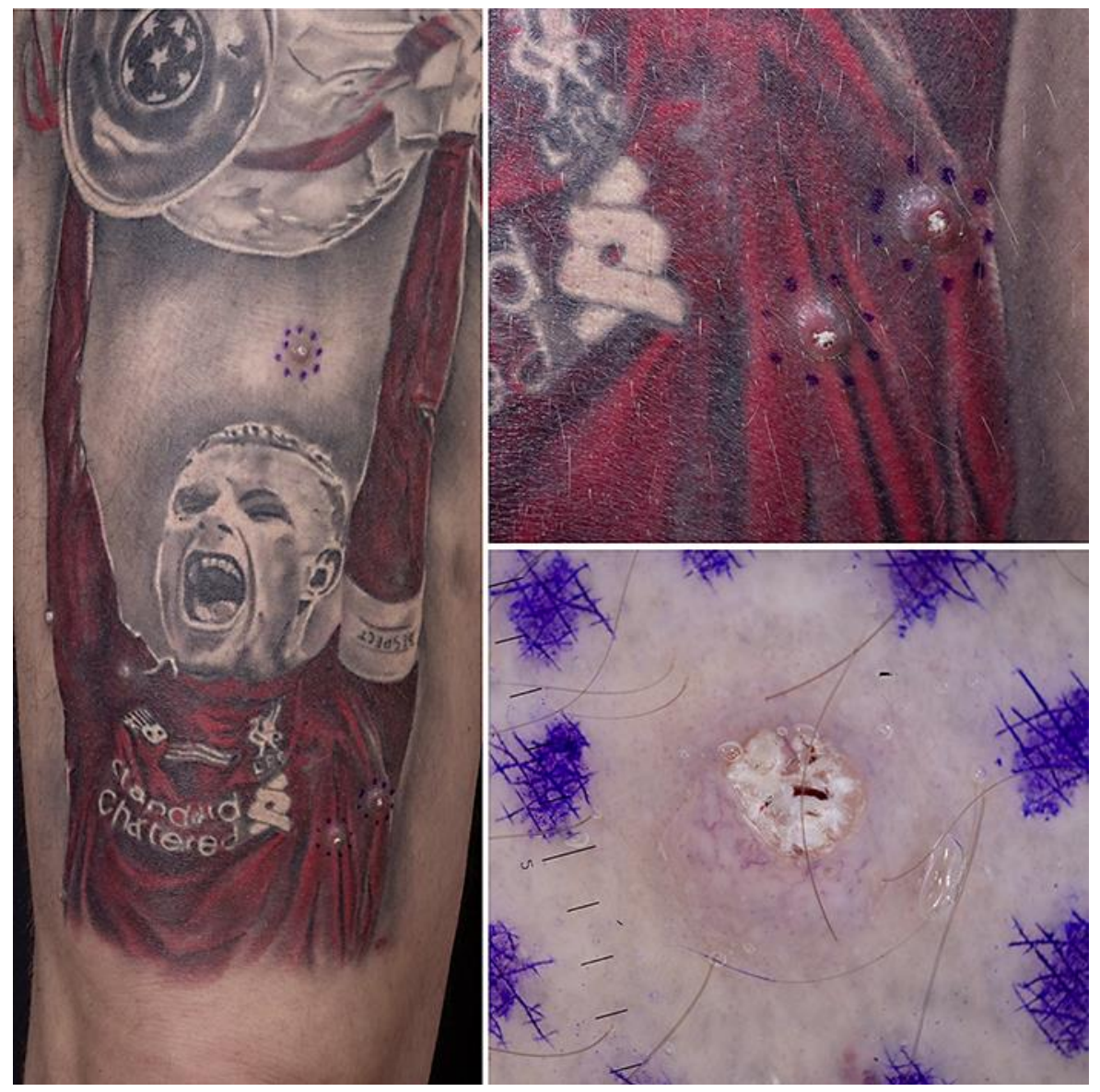

Fig. 1. Panoramic and close-up views of the tattoo on the right thigh showing seven erythematous domeshaped papules with a central thin crust. Five tumors are located within red-inked and two within black/gray-inked areas.
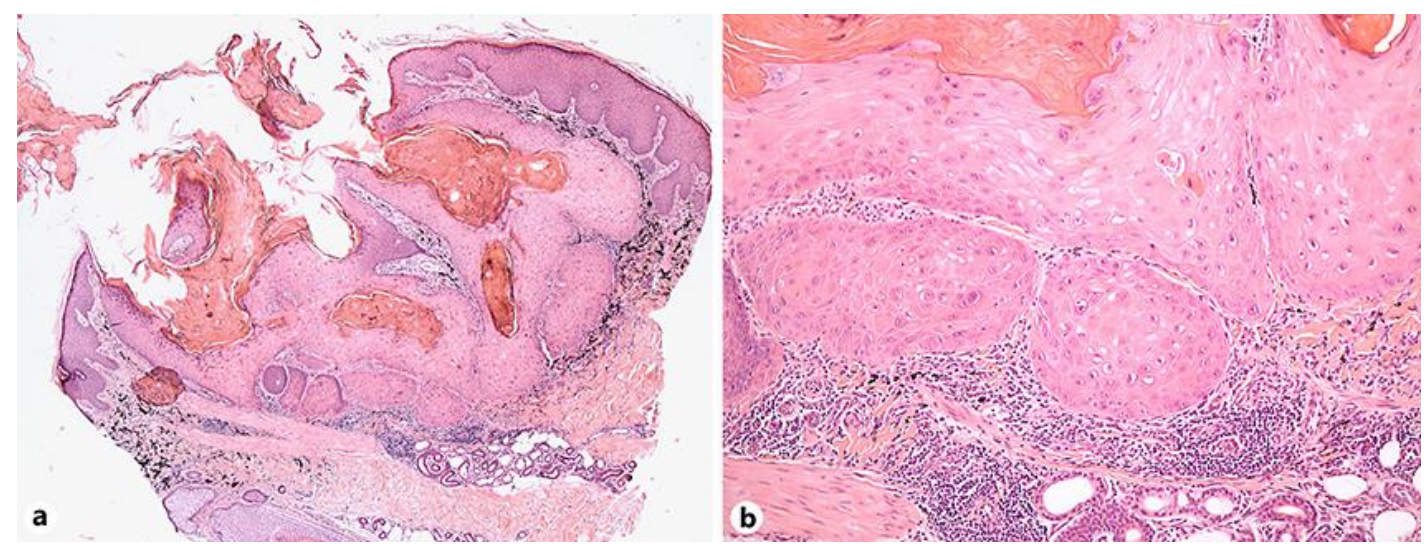

Fig. 2. Section showing a symmetrical tumor with a keratin-filled crater and epithelial lips. Note the pigment beneath the tumor. Hematoxylin and eosin stain; $\mathbf{a} \times 25, \mathbf{b} \times 100$. 